\title{
FATTY ACID PROFILE AND OXIDATIVE STRESS OF THIGH MUSCLES IN CHICKENS FED THE RATION ENRICHED IN LYCOPENE, SELENIUM COMPOUNDS OR FISH OIL*
}

\author{
Agnieszka Justyna Rozbicka-Wieczorek ${ }^{1}$, Edyta Więsyk ${ }^{1}$, Franciszek Brzóska², Bogdan Śliwiński², \\ Jan Kowalczyk ${ }^{1}$, Marian Czauderna ${ }^{1 *}$ \\ ${ }^{1}$ The Kielanowski Institute of Animal Physiology and Nutrition, Polish Academy of Sciences, \\ 05-110 Jabłonna, Poland \\ ${ }^{2}$ Department of Animal Nutrition and Feed Science, National Research Institute of Animal Production, \\ 32-083 Balice n. Kraków, Poland \\ •Corresponding author: m.czauderna@ifzz.pan.pl
}

\begin{abstract}
The aim of the study was to determine the influence of the addition for 6 weeks of $12 \mathrm{ppm}$ lycopene (Lyc), $2 \%$ fish oil (FO) or $0.25 \mathrm{ppm}$ Se as selenate $\left(\mathrm{Se}^{\mathrm{VI}}\right)$ or selenized yeast (SeY) to an isoenergetic and isonitrogenous ration containing sunflower oil as the source of energy on the profile of fatty acids (FA) and the oxidative stress in thigh muscles of female and male chickens. The ration with FO most efficiently increased the concentration of saturated fatty acids (SFA), atherogenic SFA and thrombogenic SFA as well as the concentration sum of all assayed FA in muscles of chickens. The rations with $\mathrm{Lyc}, \mathrm{Se}^{\mathrm{VI}}$ or $\mathrm{SeY}$ revealed negligible and inconsistent impact on the concentration of individual SFA in muscles compared with the control. The ration with FO most efficiently increased the concentration of polyunsaturated FA (PUFA), especially $n$ - 3 long-chain PUFA and the sum of conjugated linoleic acid isomers in muscles. The ration with $\mathrm{SeY}$ most effectively increased the concentration of long-chain PUFA (LPUFA), especially $n-6$ LPUFA, in muscles of chickens. The FO, Lyc or Se ${ }^{\mathrm{VI}}$-fed chickens had a lower concentration of cholesterol in muscles than the control or SeY fed birds. Lyc added to the ration most efficiently stimulated the accumulation of $\alpha$-tocopherol in muscles of chickens. The ration with $\mathrm{Se}^{\mathrm{VI}}$ most effectively stimulated the formation of malondialdehyde in muscles.
\end{abstract}

Key words: chickens, lycopene, selenium, fish oil, thigh muscles, fatty acids, malondialdehyde

To increase poultry meat production, parameters such as the edible parts of carcass composition and muscle fatty acid (FA) composition need to be taken into consideration. The lipid composition of chicken muscles can be modified by the supplementation of rations with small quantities of antioxidants (e.g. tocopherols, lycopene or Se-compounds), vegetable oils and fish meal or fish oil (FO) rich in long-chain polyunsaturated fatty acids (LPUFA) (Czauderna et al., 2007; Boileau

*This study was supported by the statutory funds from the National Research Institute of Animal Production (Balice n. Kraków, Poland) and the Kielanowski Institute of Animal Physiology and Nutrition, Polish Academy Sciences (Jabłonna, Poland). 
et al., 2002; Heber and Lu, 2002; Rao and Agarwal, 1998; Rozbicka-Wieczorek et al., 2012). Dietary FO may reduce the desaturation of $n-6$ FA, with a subsequent lowering of plasma lipid concentration (Farhoomand and Checaniazer, 2009). The profile of FA, especially unsaturated fatty acids (UFA), of the chicken carcass may be affected considerably by dietary Se-compounds, lycopenes or tocopherols (Czauderna et al., 2012; Demirel et al., 2004; Navarro-Alarcon and Cabrera-Vique, 2008; Rey et al., 2004; Rozbicka-Wieczorek et al., 2012). Diverse dietary Se-compounds are metabolized to Se-proteins containing Se-cysteine (Se-Cys). The essential physiological roles of half of the Se-proteins are to maintain the appropriate metabolism of arachidonic acid (AA) and low levels of free radicals or pre-oxides within cells, thus reducing oxidative stress and peroxidative damage of lipids and mono- (MUFA) or polyunsaturated fatty acids (PUFA) in living organisms (Schweizer et al., 2005; Yu et al., 2008). Indeed, following peroxidative damage of PUFA, their peroxidation products are converted by consecutive reactions of oxidation, into carbonyl species, including malondialdehyde (MDA) (Czauderna et al., 2011).

Se-compounds have the ability of removing radicals and reactive oxygen species (Rayman, 2004; Burk and Hill, 2005). Studies on laboratory animals documented that the concentration of Se in rations was positively correlated with the level of PUFA in tissues, phospholipids in serum and cholesterol esters (Pappas et al., 2008; Yu et al., 2008). Similarly, dietary lycopene (Lyc) decreased oxidative stress and peroxidative damage of unsaturated fatty acids (UFA) and lipids in living organisms (Heber and Lu, 2002; Rao and Agarwal, 1998; Rozbicka-Wieczorek et al., 2012). According to Sicilia et al. (2005) daily doses of $15 \mathrm{mg}$ of Lyc can be used to investigate the bioavailability, metabolism and mechanism of action of Lyc in calves. Considering these facts, we hypothesized that the rations enriched in Lyc or Se as selenate $\left(\mathrm{Se}^{\mathrm{VI}}\right)$ or selenized yeast $(\mathrm{SeY})$ decrease the peroxidation yield of PUFA in thigh muscles of chickens compared with the control chickens and especially chickens fed the ration containing FO. Considering the above, the aim of the current study was to investigate the impact of $\mathrm{Lyc}, \mathrm{Se}{ }^{\mathrm{VI}}$, SeY or odourless $\mathrm{FO}$ added to the ration on the concentration of selected FA, especially UFA, as well as MDA in the thigh muscles of female and male chickens.

\section{Material and methods}

\section{Chickens, housing, nutrition and experimental design}

One hundred and eighty two one-day-old non-sexed hybrid Ross-308 chicks were purchased from a commercial hatchery and raised in 5 groups, each having 35-38 chicks, with four replications, 8-9 chicks per replication. The bird room temperature, air exchange, and humidity were maintained according to the recommendations for hygiene for young chickens. The investigation was carried out in accordance with established standards for use in chickens. The protocol was approved by the local ethics and scientific authorities. Birds were kept in metal cages $\left(18\right.$ chicks $/ \mathrm{m}^{2}$ ), on litter from deciduous trees. Each day of the experiment, the number of birds in pens was controlled so as to be in line with Council Directive 
2007/43/EC. Thus, at the end of the study, there were below $33 \mathrm{~kg}$ of liveweight of chickens per $\mathrm{m}^{2}$. Throughout the experiment, feed and water were provided for $a d$ libitum consumption. Starter (1-21 days) and grower (22-42 days) rations were formulated based on maize-wheat-soyabean meal as was presented in our recent study (Rozbicka-Wieczorek et al., 2012). Basal and experimental rations were formulated to be isoenergetic and isonitrogenous. Ingredients and chemical composition of the basal rations (i.e., starter and grower) and vitamin-mineral premix are reported in detail in previous paper (Rozbicka-Wieczorek et al., 2012). The ingredients in the rations were determined by chemical analysis (AOAC, 2005). All rations were enriched in sunflower oil (SO) as the source of energy (Table 1). The level of Se in the basal ration (before addition of vitamin-mineral premix) was $0.05-0.06 \mathrm{mg} / \mathrm{kg}$, while a trace amount of vitamin E was detected in this basal ration (Brzóska et al., 2003). The level of Se as sodium selenite in vitamin-mineral premix added to starter and grower rations was $55 \mathrm{mg} / \mathrm{kg}$ premix (Rozbicka-Wieczorek et al., 2012). Starter and grower rations were supplemented with $0.5 \%$ of vitamin-mineral premix (Rozbicka-Wieczorek et al., 2012). Prior to feeding chickens, all experimental rations (i.e., starter and grower) were supplemented with $12 \mathrm{ppm}$ Lyc, $0.25 \mathrm{ppm} \mathrm{Se}$ (as Se ${ }^{\mathrm{VI}}$ or $\mathrm{SeY}$ ) or $2 \% \mathrm{FO}$; the experimental design is shown in Table 1 . Freshly prepared basal and experimental rations were administered as a powder. During the experiment, feed consumption was monitored and feed intake was calculated per kg body weight gain (BWG) of chickens; mortality also was monitored (Rozbicka-Wieczorek et al., 2012). On the fifth day of breeding, the chicks were vaccinated against Gumboro disease and on the twelfth day, against the Newcastle disease (NCD). The vaccines against Gumboro and NCD were supplied by CEVAC® IBD L and Intervet Sp. z o.o. (Poland), respectively. For a total of eight times in intervals of a few days during the entire experimental period the birds were fed a Vitasol vitamin mixture (as a lyophilizate in water). Vitasol (BIOWET DRWALEW S.A., Poland) increased survival and the BWG of birds. On day 43 of the experimental period, twelve chickens from each group, 6 female chickens $(+)$ and 6 male chickens $\left({ }^{\top}\right)$, were randomly selected. Selected chickens were slaughtered by decapitation after stunning. The right and left thigh muscles were removed, weighed, homogenized, and frozen at $-32^{\circ} \mathrm{C}$ until chemical analyses. Each right thigh muscle was chemically analysed individually.

Table 1. The experimental design and the composition of the control and experimental rations

\begin{tabular}{l|c}
\hline \multicolumn{1}{c|}{ Group } & Additives $^{1}$ added to the basal ration \\
\hline I Control group & $4 \% \mathrm{SO}$ \\
II & $2 \% \mathrm{SO}$ and $2 \% \mathrm{FO}^{2}$ \\
III & $4 \% \mathrm{SO}$ and $12 \mathrm{ppm} \mathrm{Lyc}$ \\
IV & $4 \% \mathrm{SO}$ and $0.25 \mathrm{ppm} \mathrm{Se} \mathrm{as} \mathrm{Se} \mathrm{VI}^{\mathrm{VI}}$ \\
V & $4 \% \mathrm{SO}$ and $0.25 \mathrm{ppm} \mathrm{Se}$ as SeY \\
\hline
\end{tabular}

${ }^{1} \mathrm{FO}$ - odorless fish oil; Lyc - lycopene; Se ${ }^{\mathrm{VI}}$ - sodium selenate; SeY - selenized yeast; SO - sunflower oil.

${ }^{2}$ The iodine value of FO: $50-65 \mathrm{~g} / 100 \mathrm{~g} \mathrm{FO}$; the acid value of FO: $20 \mathrm{mg} \mathrm{KOH} / \mathrm{g} \mathrm{FO}$; the fatty acid profile of FO: C14:0 3.3\%; C14:1 0.3\%; C15:0 0.2\%; C16:0 10.5\%; C16:1 3.9\%; C16:2 0.3\%; C16:3 0.2\%; C17:0 $0.2 \%$; C17:1 0.1\%; C18:0 2.5\%; transC18:1 (tC18:1) 0.5\%; c9C18:1 31.8\%; c11C18:1 3.0\%; other cC18:1 0.4\%; C18:2n-6 10.4\%; C18:3n-3 3.9\%; C20:0 0.3\%; C18:4n-3 1.2\%; c11C20:1 5.9\%; c11c14C20:2 0.9\%; c8c11c14C20:3 0.2\%; C20:4n-6 0.3\%; C20:5n-3 4.0\%; C22:0 0.1\%; cis13C22:1 6.6\%; C22:4n-6 0.3\%; C22:5n-3 $1.6 \%$; $222: 6 n-35.6 \%$; $\mathrm{C} 24: 00.1 \%$; $224: 10.5 \%$. 


\section{Reagents and chromatographic equipment}

All organic solvents were of HPLC grade and chemicals were analytical grade. $\mathrm{KOH}, \mathrm{NaOH}$, conc. $\mathrm{HCl}$, dichloromethane and $\mathrm{Na}_{2} \mathrm{SO}_{4}$ were purchased from $\mathrm{POCH}$ (Gliwice, Poland). Methanol, acetonitrile and n-heptane (99\%) were obtained from Lab-Scan (Ireland), whereas the CLA isomer mixture (2.1\% trans, transCLA, 7.1\% cis 11 ,trans 13 CLA, $40.8 \%$ cis 9 , trans 11 CLA, $41.3 \%$ trans 10 , cis 12 CLA, $6.7 \%$ cis 8 , trans 10CLA and 2.0\% cis, cisCLA) by the Industrial Chemistry Research Institute in Warsaw (Poland). Fatty acid methyl ester standards, $25 \% \mathrm{BF}_{3}$ in methanol and sodium selenate $\left(\mathrm{Se}^{\mathrm{VI}}\right)$ were purchased from Supelco and Sigma-Aldrich Co. (St. Louis, MO, USA). SeY (Se-Saccharomyces cerevisiae) was obtained from SelPlex (Alltech Inc., USA). About $83 \%$ of the total Se content of SeY represents Se in the form of seleno-methionine (Se-Met) and 5\% in the form of seleno-cysteine (SeCys) incorporated into the proteins of Saccharomyces cerevisiae (Rayman, 2004); the chemical profile of SeY was presented in our previous studies (Czauderna et al., $2009 \mathrm{c}$ ). The starter ration contained (mg/kg ration): C10:0 28, C12:0 34, C14:0 144, C16:0 4260, C17:0 42, C18:0 907, C18:1n-9 9470, C18:2n-6 11370, C18:3n-3 1380, C20:1n-9 107, C20:2n-6 18, C24:1n-9 24, C22:5n-3 30 and C22:6n-3 13. The grower ration contained (mg/kg ration): C10:0 38, C12:0 45, C14:0 160, C16:0 3570; C18:0 620, C18:1n-9 11610, C18:2n-6 14080, C18:3n-3 1990, C20:1n-9 198, C22:5n-3 38 and $\mathrm{C} 22: 6 n-36$.

Trichloroacetic acid, 2,6-di-tert-butyl-p-cresol, 1,1,3,3-tetra-methoxypropane (99\%) and 2,4-dinitrophenylhydrazine (DNPH), containing about 30\% water were supplied by Sigma-Aldrich (St. Louis, MO, USA). Lycopene (Lyc), 10\% in sunflower oil (LycoVit Dispersion 10\%) was obtained from BASF The Chemical Company (Germany). SO was donated by Company AGROSOL (Pacanów, Poland), while FO, by Meals Manufacturing Company ZPM (Bokiny-Łapy, Poland). The fatty acid composition (\%) of SO in the rations was as follows: C12:0 0.05, C14:0 1.9, C16:0 5.4, C16:1 0.3, C17:0 0.2, C17:1 0.03, C18:0 2.7, cis9C18:1 (c9C18:1) 39.1, c9c12C18:2 48.3, c9c12c15C18:3 0.3, C20:0 0.25, C20:1 0.14, C22:0 0.9, C22:1 $0.15, \mathrm{C} 22: 2 \sim 0.05, \mathrm{C} 24: 00.25$ and $\mathrm{C} 24: 1 \sim 0.27$.

\section{Saponification, methylation of fatty acids, gas chromatographic equipments and analyses}

Homogenized muscles (45-50 mg) were saponificated using $\mathrm{KOH}$ solutions according to Czauderna et al. (2009 a). Fatty acids in hydrolysates were extracted according to Czauderna et al. (2009 a) followed by methylations (Czauderna et al., 2009 a). Esterified fatty acids (FAME) in muscles and standards were quantified using gas chromatography with mass spectrometry according to Rozbicka-Wieczorek et al. (2012). The analyses of FAME in muscles were performed on a SHIMADZU GC-MS-QP2010 Plus EI equipped with a BPX70 fused silica capillary column $(120 \mathrm{~m} \times 0.25 \mathrm{~mm}$ i.d. $\times 0.25 \mu \mathrm{m}$ film thickness; SHIM-POL, quadrupole mass selective detector (Model 5973N) and injection port. FAME identification was validated based on electron impact ionization spectra of FAME and compared with authentic FAME standards and NIST 2007 reference mass spectra library. 


\section{Derivatisation of MDA in muscles, liquid chromatographic equipments and analyses}

The MDA concentrations in muscle were determined after saponification followed by derivatization with DNPH to MDA-DNPH according to Czauderna et al. (2011). The chromatographic separation of MDA-DNPH from muscles was conducted using an ultra-fast liquid chromatography system (SHIMADZU, Kyoto, Japan), incorporating two LC-20ADXR liquid chromatographic pumps (UFLCXR), a SIL-20ACXR autosampler (LFLCXR), a CBM-20A communications bus module (UFLC), a CTO-20A column oven, a DGU-20A5 degasser, and a SPD diode array detector. The column was a Phenomenex C18-column (Synergi $2.5 \mu \mathrm{m}$, Hydro-RP, $100 \AA, 100 \mathrm{~mm}$ in length) with an inner diameter of $2 \mathrm{~mm}$. MDA was analysed using the gradient of acetonitrile in water and the photodiode detection (Czauderna et al., 2011). The concentration of MDA was calculated based on the fresh weight of muscle samples.

\section{Determination of $\alpha$-tocopherol $(\alpha-\mathrm{T})$ and cholesterol in muscles by HPLC}

The concentration of $\alpha$-tocopherol $(\alpha-T)$ and cholesterol in muscle samples was determined after alkaline saponification followed by quantification using high performance liquid chromatography with photodiode detection according to Czauderna et al. (2009 b).

\section{Statistical analyses}

Results are presented as means of individually analysed samples of muscles. Differences between treatment means were tested by Duncan's Multiple Range Test, using $\mathrm{P} \leq 0.05$ and $\mathrm{A}, \mathrm{B}-\mathrm{P} \leq 0.01$ as the threshold for statistical significance. Statistical analyses between the female chickens and male chickens were tested by Student's t-test. Statistical analyses of interactions (antioxidants $\times$ gender of chickens) were performed using two-factorial ANOVA analysis. All statistical analyses were performed using System SAS 'Local' XP-PRO Enterprise Guide, version 4.3 (4.3.0.11123) C44010.

\section{Results}

\section{The effect of the experimental rations on the saturated fatty acid concentra- tion of muscles}

As shown in Table 2, the ration enriched in FO statistically or numerically increased the concentrations of individual saturated fatty acids (SFA), the concentration sum of all assayed SFA, atherogenic (A-SFA) and thrombogenic (T-SFA) saturated fatty acids in muscles of chickens compared with the control (Group I). Concomitantly, FO added to the ration most effectively increased the concentration sum of all assayed fatty acids in thigh muscles of chickens. The rations with Lyc, $\mathrm{Se}^{\mathrm{VI}}$ or SeY revealed negligible and inconsistent impact on the concentration of individual SFA in muscles of chickens compared with the control. The ration with $\mathrm{Se}^{\mathrm{VI}}$ or SeY numerically or statistically decreased values of indexes of A-SFA ( ${ }_{\text {index }} \mathrm{A}^{\mathrm{SFA}}$ ) and T-SFA $\left({ }_{\text {index }} \mathrm{T}^{\mathrm{SFA}}\right)$ in muscles of chickens compared with the control and other ex- 
perimental groups. Our studies showed the significant positive influence of the ration enriched in $\mathrm{FO}, \mathrm{Se}^{\mathrm{VI}}$ or $\mathrm{SeY}$ on the PUFA/SFA ratio in muscles of chickens compared with the control and Lyc-fed chickens. The ration containing Lyc revealed minute influence on the value of the PUFA/SFA ratio in muscles of chickens compared with the control.

The effect of the experimental rations on the content of MUFA and PUFA in muscles

The ration with FO most efficiently stimulated the accumulation of cis $9 \mathrm{C} 16: 1$ ( $c 9 \mathrm{C} 16: 1)$ and $c 9 \mathrm{C} 18: 1$ and the concentration sum of monounsaturated FA (MUFA) in muscles of chickens (Table 3). The ration with $\mathrm{Se}^{\mathrm{VI}}$ numerically decreased the concentration of $c 9 \mathrm{C} 16: 1, c 9 \mathrm{C} 18: 1$ and MUFA in muscles of chickens compared with the control. There are no treatment effects on values of $\Delta 9$-desaturase index in muscles of chickens. The values of $\Delta 9$-desaturase index for $\mathrm{C} 18: 0$ are higher than the values of this index for $\mathrm{C} 16: 0$ and $\mathrm{C} 14: 0$; the values of the $\Delta 9$-desaturase index for C14:0 are close to zero (i.e., ${ }_{\text {118:0 }} \Delta 9>_{\text {C16:0 }} \Delta 9>_{\text {C14:0 }} \Delta 9$ ).

Birds that consumed the FO ration had the greatest levels of $c 7 c 10 c 13 c 16 c 19 \mathrm{C} 22: 5$ (DPA), $c 4 c 7 c 10 c 13 c 16 c 19 \mathrm{C} 22: 6$ (DHA), the sum of $n$-3 long-chain PUFA ( $n-3$ LPUFA) in muscles of chickens (Tables 3 and 4). The ration with FO resulted in the highest concentration sum of CLA isomers ( $\Sigma$ CLA), especially $t 7 c 9$ CLA isomer, in muscles of chickens. The ration with FO reduced the concentration of arachidonic acid (AA) in muscles of chickens, whereas considerably increased the concentration of LPUFA (without $n$-6 LPUFA) in muscles of chickens.

The ration with SeY increased the accumulation of PUFA, including $\Sigma$ CLA, LA, AA, DHA and LPUFA, including n-6 LPUFA, in muscles of chickens compared with the control (Tables 3 and 4). SeY added to the ration statistically or numerically significantly increased the values of the elongase index $\left(\mathrm{El}_{\text {index }}\right)$ and $\Delta 4$-desaturase indexes $\left(\Delta 4_{\text {index }}\right)$ in muscles of chickens compared with the control. The ration with Lyc most significantly increased the value of $\mathrm{El}_{\text {index }}$ in muscles of chickens. The rations with $\mathrm{Se}^{\mathrm{VI}}$ or $\mathrm{SeY}$ increased values of the PUFA/SFA ratio in muscles of chickens compared with the control. The ration with $\mathrm{Se}^{\mathrm{VI}}$ or $\mathrm{SeY}$ numerically increased the LPUFA/SFA ration in muscles of chickens compared with the LPUFA/SFA ration in muscles of chickens fed the ration containing FO or Lyc.

\section{The impact of the experimental rations on the concentration of MDA, $\alpha$-tocopherol and cholesterol in muscles}

The inclusion of dietary Lyc most significantly increased the concentration of $\alpha$-tocopherol $(\alpha-\mathrm{T})$ in muscles of chickens; muscles of male chickens had the higher concentration of $\alpha$-T than muscles of female chickens (Table 5). The supplementation of $\mathrm{FO}, \mathrm{Se}^{\mathrm{VI}}$ or SeY numerically decreased the concentration of $\alpha-\mathrm{T}$ in muscles of chickens compared with the control and especially Lyc-fed chickens. 


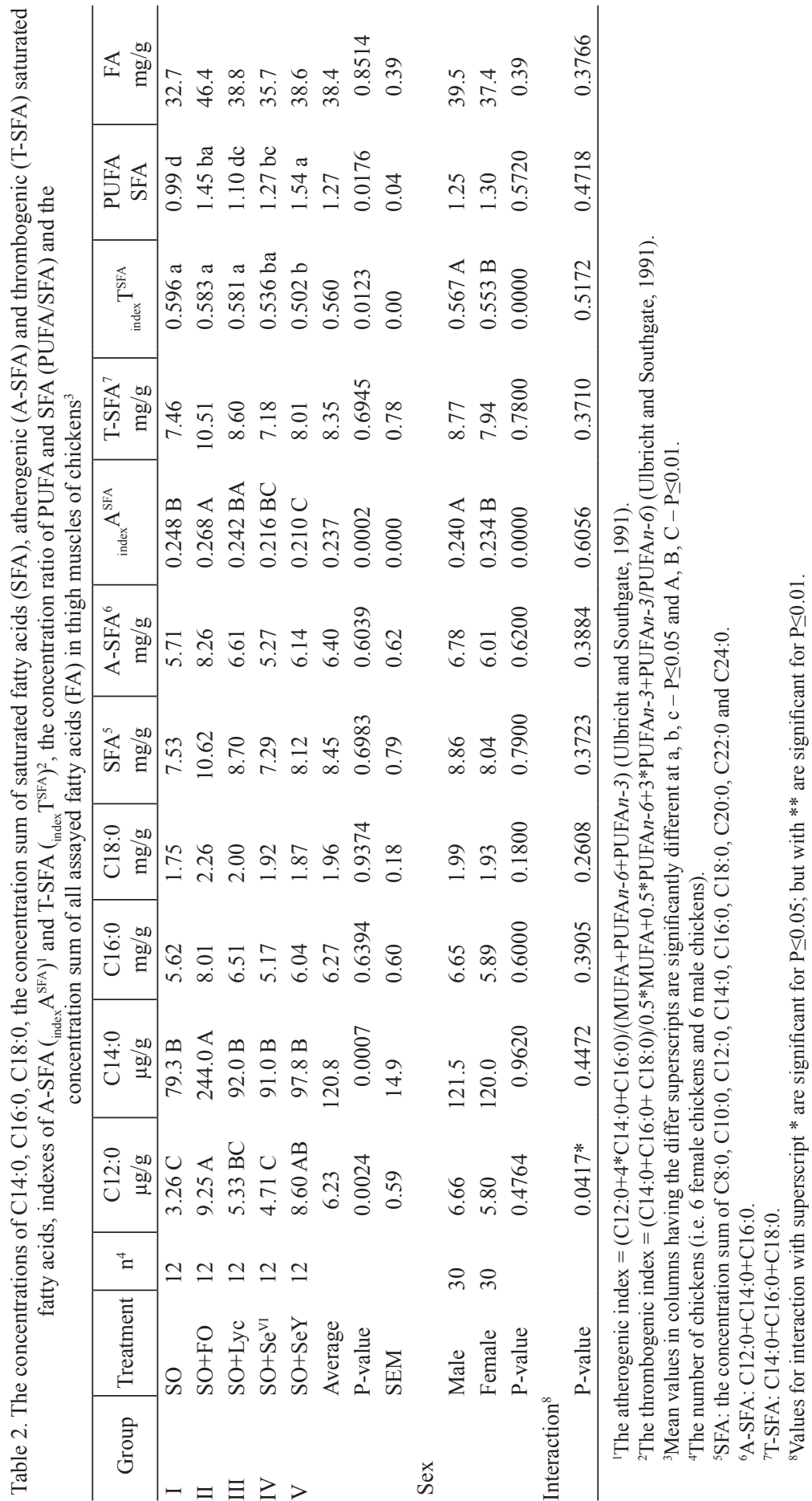




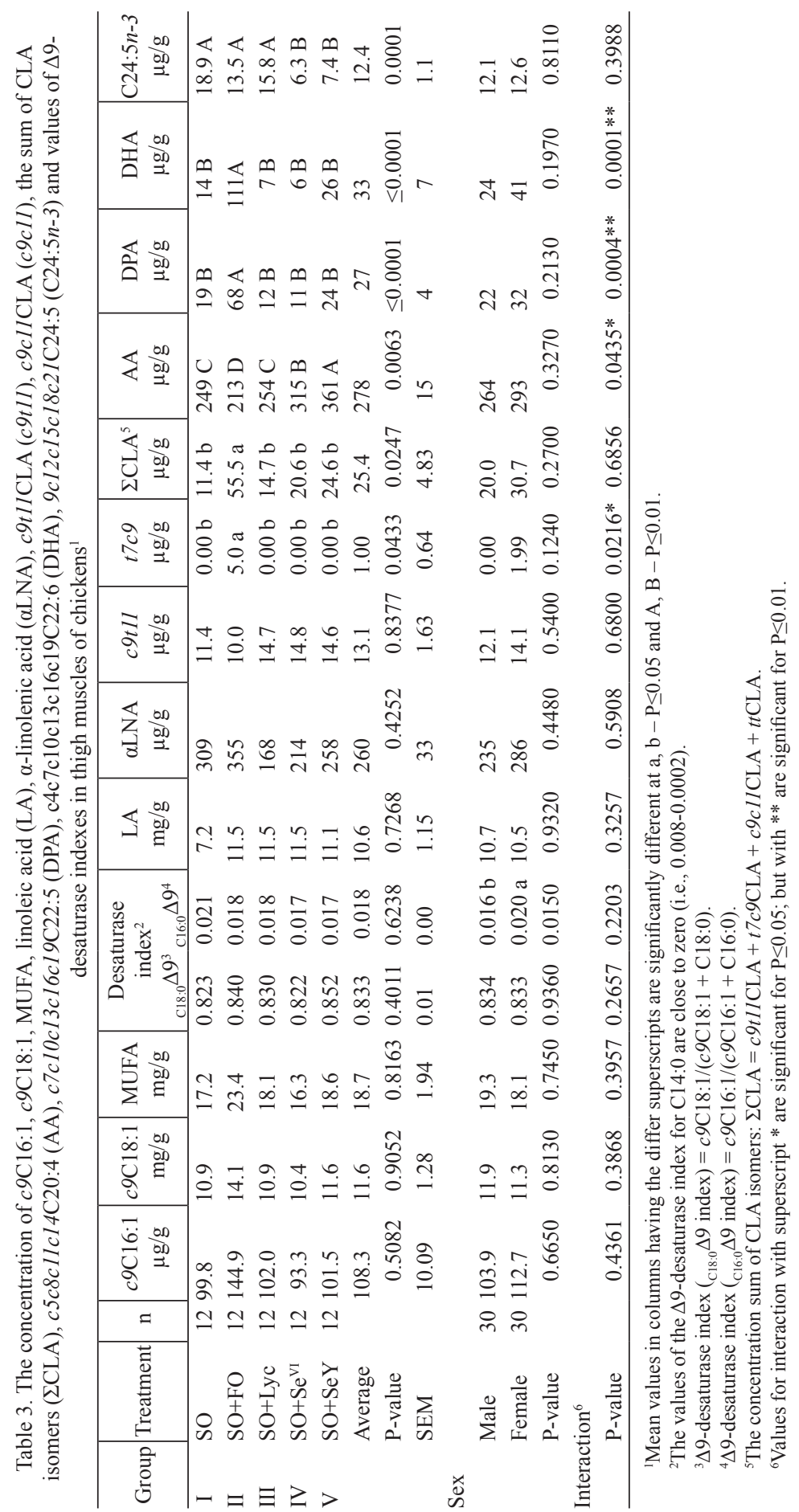




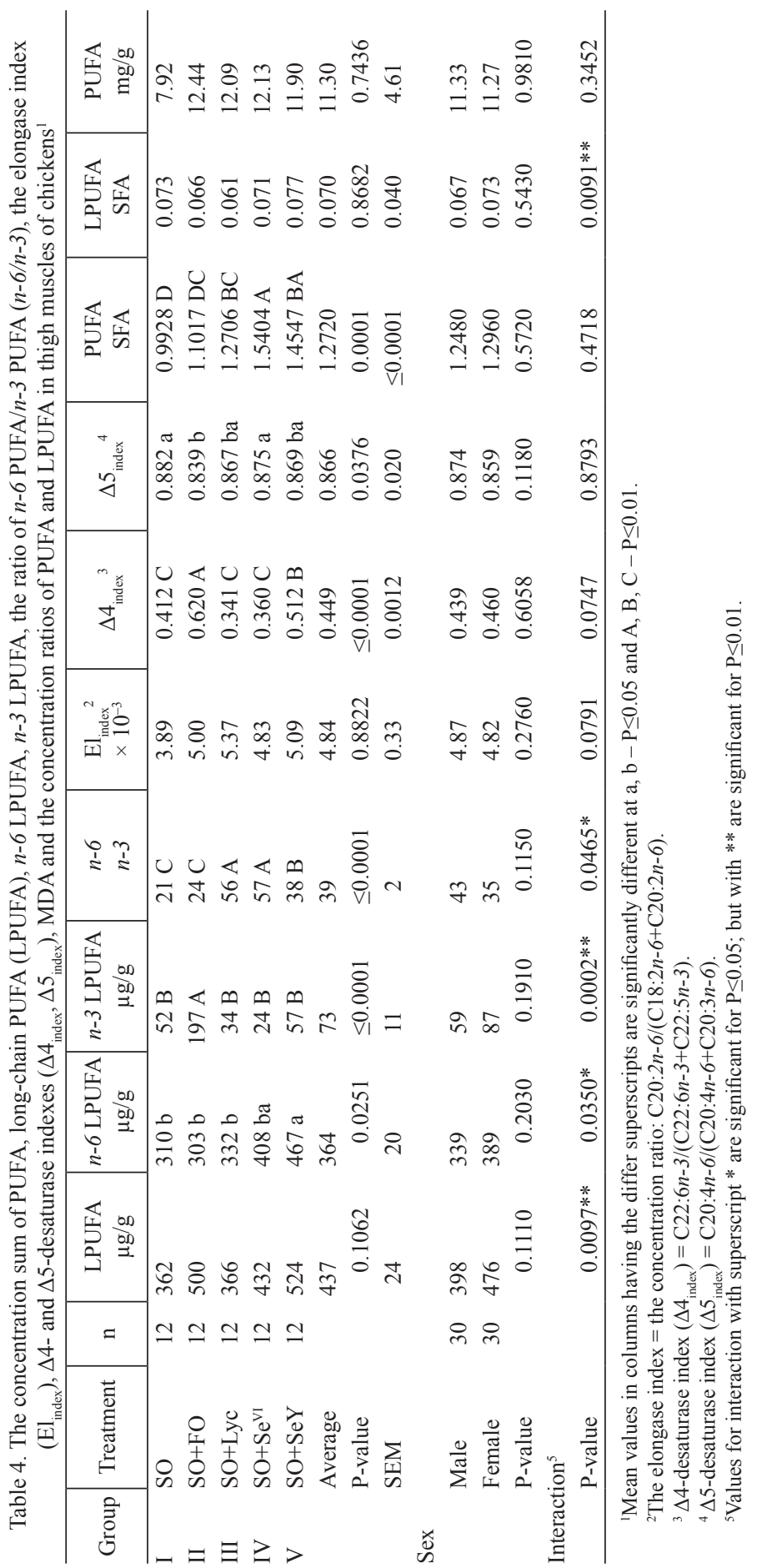


Feeding chickens with $\mathrm{Se}^{\mathrm{VI}}$ or $\mathrm{FO}$ enriched ration can be considered as a possible way to decrease the concentration of cholesterol in muscles of chickens. Moreover, the ration with Lyc numerically decreased the concentration of cholesterol in muscles of chickens compared with the control birds. On the other hand, the ration with SeY revealed negligible influence on the concentration of cholesterol in muscles of chickens compared with the control.

Table 5. The concentrations of $\alpha$-tocopherol ( $\alpha$-T) and cholesterol, MDA and values of PUFA peroxidation index $\left(\mathrm{MDA}_{\text {index }}\right)^{1}$ in thigh muscles of chickens ${ }^{2}$

\begin{tabular}{|c|c|c|c|c|c|c|}
\hline Group & Treatment & $\mathrm{n}$ & $\begin{array}{c}\alpha \text {-tocopherol } \\
\mu \mathrm{g} / \mathrm{g}\end{array}$ & $\begin{array}{c}\text { Cholesterol } \\
\mathrm{mg} / \mathrm{g}\end{array}$ & $\begin{array}{c}\mathrm{MDA} \\
\mathrm{ng} / \mathrm{g}\end{array}$ & $\mathrm{MDA}_{\text {index }}$ \\
\hline I & $\mathrm{SO}$ & 12 & 2.05 & 1.29 & 0.622 & 1.138 \\
\hline II & $\mathrm{SO}+\mathrm{FO}$ & 12 & 1.63 & 0.89 & 0.700 & 1.110 \\
\hline III & SO+Lyc & 12 & 2.79 & 1.18 & 0.625 & 1.097 \\
\hline IV & $\mathrm{SO}+\mathrm{Se}^{\mathrm{VI}}$ & 12 & 1.72 & 0.99 & 0.873 & 1.125 \\
\hline \multirow[t]{4}{*}{ V } & $\mathrm{SO}+\mathrm{SeY}$ & 12 & 1.63 & 1.26 & 0.748 & 1.073 \\
\hline & Average & & 1.96 & 1.12 & 0.714 & 1.109 \\
\hline & P-value & & 0.1825 & 0.5267 & 0.1772 & 0.4229 \\
\hline & SEM & & 0.18 & 0.46 & 0.040 & 0.010 \\
\hline \multicolumn{7}{|l|}{ Sex } \\
\hline & Male & 30 & $2.36 \mathrm{a}$ & 1.03 & 0.752 & 1.114 \\
\hline & Female & 30 & $1.57 \mathrm{~b}$ & 1.22 & 0.676 & 1.103 \\
\hline & P-value & & 0.0253 & 0.2491 & 0.2687 & 0.5582 \\
\hline \multicolumn{7}{|c|}{ Interaction $^{3}$} \\
\hline & P-value & & 0.1608 & 0.9146 & 0.7423 & 0.8185 \\
\hline
\end{tabular}

${ }^{1}$ PUFA peroxidation index $\left(\mathrm{MDA}_{\text {index }}\right)-\mathrm{MDA}_{\text {index }}=[\mathrm{MDA}(\mathrm{ng} / \mathrm{g})+\mathrm{PUFA}(\mathrm{mg} / \mathrm{g})] / \mathrm{PUFA}(\mathrm{mg} / \mathrm{g})($ RozbickaWieczorek et al., 2012).

${ }^{2}$ Mean values in columns having the different superscripts are significantly different at $\mathrm{a}, \mathrm{b}-\mathrm{P} \leq 0.05$.

${ }^{3}$ Values for interaction with superscript * are significant for $\mathrm{P} \leq 0.05$; but with ** are significant for $\mathrm{P} \leq 0.01$.

The concentration of MDA in muscles of chickens numerically increased with the ration containing $\mathrm{FO}, \mathrm{SeY}$ and especially $\mathrm{Se}^{\mathrm{VI}}$ compared with the control and Lyc-fed chickens. FO, Lyc, $\mathrm{Se}^{\mathrm{VI}}$ or $\mathrm{SeY}$ added to the ration numerically decreased the values of PUFA peroxidation index $\left(\mathrm{MDA}_{\text {index }}\right)$ in muscles of chickens compared with the control.

\section{Discussion}

In the current studies, no macroscopic lesions and pathological changes were found in all internal organs, adipose tissues and muscles of broiler chickens fed the experimental rations supplemented with $\mathrm{Lyc}, \mathrm{Se}$ (as $\mathrm{Se}^{\mathrm{VI}}$ or $\mathrm{SeY}$ ) or FO. Indeed, only long-term intake of diets containing $\geq 5 \mathrm{ppm}$ as inorganic Se compounds (especially selenite and selenide) can be hepatotoxic and teratogenic in humans and animals. Fortunately, in contrast to selenite, $\mathrm{Se}^{\mathrm{VI}}$ and especially $\mathrm{SeY}$ are less toxic and reac- 
tive in living organisms (Tapiero et al., 2003; Navarro-Alarcon and Cabrera-Vique, 2008; Weiss and Hogan, 2005). Moreover, Se-Met, the main chemical form of Se in $\mathrm{SeY}$ is least reactive, as $\mathrm{tRNA}_{\mathrm{Met}}$ does not discriminate between methionine and Se-Met. Thus, Se-Met originated from dietary SeY is incorporated into proteins of animal and human body in place of methionine (Tapiero et al., 2003; Rayman, 2004). Considering the above, we argue that Se-Met as Se-Met residue in proteins is a stable and safe-storage mode for dietary SeY in the body of chickens as well as other farm animals and humans.

\section{The effect of the experimental rations on the fatty acid concentration of muscles}

The effects of the experimental rations on the concentration of SFA, MUFA and PUFA in thigh muscles of chickens are summarized in Tables 2, 3 and 4. Our results documented that supplementation of FO increased the yield of de novo synthesis of fatty acids and/or more efficiently decreased the capacity of $\beta$-oxidation of fatty acids in thigh muscles of chickens. Interestingly, recent studies documented that the ration with FO decreased the accumulation of SFA, MUFA and PUFA in breast muscles of female chickens and especially male chickens (Farhoomand and Checaniazer, 2009; Rozbicka-Wieczorek et al., 2014). Considering the above, we suggest that the effect of supplementation of FO on the yield of de novo synthesis of fatty acids and/or $\beta$-oxidation of fatty acids depends upon the type of muscles of chickens. Our results also documented that $\mathrm{SeY}$ added to the ration more efficiently increased the yield of de novo synthesis of fatty acids and/or more efficiently decreased the capacity of $\beta$-oxidation of fatty acids in thigh muscles of chickens than $\mathrm{Se}^{\mathrm{VI}}$ added to the chicken ration.

Our study documented that Lyc supplementation in the ration increased the yield of de novo synthesis of fatty acids and/or reduced the capacity of $\beta$-oxidation of fatty acids in thigh muscles of chickens. Our results are in agreement with the previous findings of Heber and Lu (2002) and Boileau et al. (2002). Lyc added to the ration has been shown to reduce the catabolic response induced by immune stimulation and may be effective in promoting growth of female and male chickens (Rozbicka-Wieczorek et al., 2012).

Unexpectedly, the ration enriched in Lyc or $\mathrm{Se}$ as $\mathrm{Se}^{\mathrm{VI}}$ or $\mathrm{SeY}$ usually numerically increased the concentration of $n-6$ LPUFA in muscles of chickens compared with the control. On the other hand, the concentration of $n-3$ LPUFA in thigh muscles decreased with the addition of Lyc or especially $\mathrm{Se}^{\mathrm{VI}}$ to the ration. Thus, the present results are in agreement with our other studies (Rozbicka-Wieczorek et al., 2014) showing that the ration with Lyc or especially $\mathrm{Se}^{\mathrm{VI}}$ reduced the concentration of $n-3$ LPUFA (e.g. DPA or DHA) in breast muscles of female and male chickens compared with the control. Considering the above, we suggest that dietary Lyc or Se ${ }^{\mathrm{VI}}$ preferentially reduced the metabolism of fatty acids into n-3 LPUFA (e.g.DPA and DHA; Tables 3 and 4) in muscles of chickens compared with the control and chickens fed the ration with SeY. The ration with SeY most significantly stimulated the metabolism, especially elongation (Table 4), of fatty acids into $n$-6 LPUFA, while slightly stimulating the yield of the biosynthesis of $n$ - 3 LPUFA (e.g.: DPA and DHA) in thigh muscles of chickens compared with the control. 
As expected, $n$-3 LPUFA (e.g. DPA and DHA) were found to be present at the highest levels in muscles of chickens when the FO was added to the ration, as compared with the control and other experimental groups. This finding could be attributed to the highest capacity of $\Delta 4$-desaturase in the thigh muscles of chickens fed the ration with FO (Table 4). The results reported here reinforce the findings of our other studies with respect to a possible role for supplementation of FO on the capacity of $\Delta 4$-desaturase and the concentration the $n$-3 LPUFA in breast muscles of female and male chickens (Rozbicka-Wieczorek et al., 2014). Considering the above, we argue that the high value of elongase index and the highest values of $\Delta 4$-desaturase index could be responsible for the high concentrations of LPUFA, especially $n$ - 3 LPUFA, in muscles of chickens fed the ration with FO.

Our investigation also documented that FO supplementation resulted in the increase in the concentration sum of CLA isomers ( $\Sigma$ CLA) in muscles of chickens (Table 3). In fact, dietary FO contains $c 11 \mathrm{C} 18: 1$ and the mixture of transC18:1 ( $t \mathrm{C} 18: 1)$ positional isomers (Table 1). Considering the above, we argue that $\Delta 9$-desaturation of especially $c 11 \mathrm{C} 18: 1, t 7 \mathrm{C} 18: 1$ and/or $t 11 \mathrm{C} 18: 1$ is responsible for the increase in the concentration of $\Sigma$ CLA in muscles of chickens compared with the control and other experimental groups.

\section{The effect of the rations on the contents of $\alpha$-tocopherol, cholesterol and MDA of muscles}

As shown in Table 5, the concentration of $\alpha$-T in muscles of male chickens was higher $(\mathrm{P} \leq 0.05)$ than in muscles of female chickens. Our results documented that $\mathrm{Se}^{\mathrm{VI}}$ added to the ration most efficiently stimulated the formation of MDA in muscles of chickens. These results indicated that dietary $\mathrm{Se}^{\mathrm{VI}}$ stimulated the oxidative stress in muscles of chickens, which in turn decreased the concentration of $\alpha-\mathrm{T}$ in muscles of chickens compared with the control and especially Lyc-fed chickens. Interestingly, SeY added to the ration decreased the accumulation of MDA in muscles of chickens compared with chickens fed the ration with $\mathrm{Se}^{\mathrm{VI}}$. Considering the above, we argued that Se-Met originated from dietary SeY is incorporated into chicken Se-proteins, which possess higher antioxidant capacity compared with the capacity of $\mathrm{Se}^{\mathrm{VI}}$ induced Se-proteins. Moreover, the ration with $\mathrm{FO}$ (rich in $n-3$ LPUFA) produced the lower concentration of MDA in muscles of chickens (Table 5) than the addition of $\mathrm{Se}^{\mathrm{VI}}$ or $\mathrm{SeY}$ to the ration containing only $\mathrm{SO}$ (rich in LA; Table 1). Considering the above, we suggest that the interaction between $\mathrm{SO}$ and $\mathrm{Se}$ (as $\mathrm{Se}^{\mathrm{VI}}$ or $\mathrm{SeY}$ ) resulted in the higher yield of formation of MDA in muscles of chickens than the interaction between SO and FO. Moreover, our results documented that $n$-3 PUFA originated from dietary FO exhibited stronger antiinflammatory properties than PUFA originated from the rations containing 4\% SO (Table 1) (BederskaŁojewska et. al., 2013; Rey et al., 2004).

The proposed index of PUFA peroxidation $\left(\mathrm{MDA}_{\text {index }}\right)$ is the better indicator of the yield of PUFA peroxidation compared with the MDA concentration as MDA index $_{\text {. }}$ takes into consideration concentrations of MDA, PUFA and a capacity of antioxidants in muscles (Table 5). Indeed, the yield of MDA formation positively correlates with the concentration of PUFA and negatively correlates with the concentrations of 
antioxidants (Czauderna et al., 2011; Heber and Lu, 2002; Rao and Agarwal, 1998). The lowest value of MDA $_{\text {index }}$ was found in muscles of chickens fed the ration containing $\mathrm{SeY}$ (the antioxidant). On the other hand, the highest value of $\mathrm{MDA}_{\text {index }}$ was found in control chicken muscles containing the lowest concentration of PUFA in muscles (Table 4; SO fed chickens).

The results obtained from our study documented that broilers that had been fed the Lyc, $\mathrm{Se}^{\mathrm{VI}}$ or FO ration had the lower concentration of cholesterol in muscles than broilers administered the control or SeY-containing ration (Table 5). Our observations are consistent with other studies in which a ration enriched in $\mathrm{Lyc}, \mathrm{Se}^{\mathrm{VI}}$ or FO (rich in $n$-3 PUFA) reduced the concentration of cholesterol in tissues of living organisms (Rey et al., 2004; Roy et al., 2011; Ševčikova et al., 2008). On the other hand, Se-Met originated from dietary SeY revealed negligible influence on the concentration of cholesterol in muscles of chickens compared with the control chickens. Indeed, Se-Met is mainly incorporated into proteins of animal and human body in place of methionine (Rayman, 2004); thus, we argued that these Se-Met-proteins have negligible influence on the de novo biosynthesis as well as accumulation of cholesterol in muscles of chickens.

In conclusion, based on values of $\mathrm{MDA}_{\text {index }}$, we argued that Lyc or SeY added to the ration more efficiently reduced the oxidative stress in thigh muscles of chickens compared with the control birds and chickens fed the ration enriched in $\mathrm{Se}^{\mathrm{VI}}$. The ration with FO most effectively increased the accumulation of anti-inflammatory fatty acids (i.e. $n$-3 LPUFA) in thigh muscles of chickens. Interestingly, the highest concentration of $n-3$ LPUFA in thigh muscles of FO fed chickens was accompanied by the lower value of $\mathrm{MDA}_{\text {index }}$ in their muscles compared with the control or $\mathrm{Se}^{\mathrm{VI}}$-fed chickens. Thus, the presented results of our study constitute important information for nutritionists carrying out further investigations to improve the nutritional quality of feed for broiler chickens and humans. Further studies are necessary to determine if dietary selenite (the antioxidant), FO and other vegetable oils (e.g. linseed oil) induce changes in concentrations of fatty acids, tocopherols, cholesterol and MDA in muscles and adipose tissues in chickens.

\section{References}

AOAC (2005). Association of Official Analytical Chemists, Official Methods of Analysis. 18th Edition. Arlington, VA.

Bederska-Łojewska D., Orczewska-Dudek S., Pieszka M. (2013). Metabolism of arachidonic acid, its concentration in animal products and influence on inflammatory processes in the human body: a review. Ann. Anim. Sci., 2: 177-194.

B o i l e a u T.W.-M., B o i l e a u A.C., Erdman J.W. (2002). Bioavailability of all-trans and cis-isomers of lycopene. Exp. Biol. Med., 227: 914-919.

Brzósk a F., B rze zi ń s k i W., B rzós k a B. (2003). Mineral nutrients in Polish feedingstuffs. Part 2. Cereal grains. Ann. Anim. Sci., 3: 311-321.

B u r k R.F., H i 11 E.K. (2005). Selenoprotein P: An extracellular protein with unique physical characteristics and a role in selenium homeostasis. Annu. Rev. Nutr., 25: 11.1-11.21.

Council Directive 2007/43/EC. (2007). Laying down minimum rules for the protection of chickens kept for meat production. Official J. Eur. Union, 12.7.2007: L 182/19 - L 182/28. 
Cza u derna M., Kow a l c zy k J., K orniluk K., N i edźw i e d zka K.M. (2007). Comparison of the influence of different chemical forms of selenium and the profiles of CLA isomers in the diet on the fatty acid and amino acid contents in the liver and femoral muscles of rats. J. Anim. Feed Sci., 16: 678-695.

Czauderna M., Kowalczyk J., Krajewska K.A., Rozbicka A.J., Michalski J. (2009 a). Dietary selenite and conjugated linoleic acid isomers influence fatty acid concentrations in the liver and femoral muscles of rats. J. Anim. Feed Sci., 18: 564-581.

Czauderna M., Kow lczyk J., Ni edźwi edzka K.M. (2009 b). Simple HPLC analysis of tocopherols and cholesterol from specimens of animal origin. Chem. Anal. (Warsaw), 54: 203-214.

C z a u d erna M., K o w a l c z y k J., N i edźw i ed zk a K.M., L e ng L., C o banova K. (2009 c). Dietary selenized yeast and CLA isomer mixture affect fatty- and amino acid concentrations in the femoral muscles and liver of rats. J. Anim. Feed Sci., 18: 348-361.

C z a u d e r n a M., K ow a l c z y k J., M a r o un e k M. (2011). The simple and sensitive measurement of malondialdehyde in selected specimens of biological origin and some feed by reversed phase high performance liquid chromatography. J. Chromatogr., B, 879: 2251-2258.

Cza derna M., K ow a l c z y k J., M a r o un ek M. (2012). Dietary linseed oil and selenate affect the concentration of fatty acids in selected tissues of sheep. Czech J. Anim. Sci., 57: 389-401.

D e mirel G., Wa chira A.M., Sinclair L.A., Wilkinson R.G., Wood J.D., Enser M. (2004). Effects of dietary $n-3$ polyunsaturated fatty acids, breed and dietary vitamin $\mathrm{E}$ on the fatty acids of lamb muscle, liver and adipose tissue. Brit. J. Nutr., 91: 551-565.

F a r h o o m and P., C h e c a n i a zer S. (2009). Effects of graded levels of dietary fish oil on the yield and fatty acid composition of breast meat in broiler chickens. J. Appl. Poultry Res., 18: 508-513.

H e b e r D., L u Q.-Y. (2002). Overview of mechanisms of action of lycopene. Exp. Biol. Med., 227: 920-923.

Navarro-Alarcon M., Cabrera-Vique C. (2008). Selenium in food and the human body: A review. Sci. Total Envir., 400: 115-141.

P a p pas A.C., Z o i d is E., S u ra i P.F., Z ervas G. (2008). Selenoproteins and maternal nutrition. Comp. Biochem. Physiol. Pt. B, 151: 361-372.

R a o A.V., A g a rw a 1 S. (1998). Bioavailability and in vivo antioxidant properties of lycopene from tomato products and their possible role in the prevention of cancer. Nutr. Cancer, 31: 199-203.

R a y m a n P.M. (2004). Review article. The use of high-selenium yeast to raise selenium status: how does it measure up? Brit. J. Nut., 92: 557-573.

Rey A.I., Lopez-Bote C.J., Kerry J.P., Lynch P.B., Buckley D.J., Morrissey P.A. (2004). Modification of lipid composition and oxidation in porcine muscle and muscle microsomes as affected by dietary supplementation of $n-3$ with either $n-9$ or $n-6$ fatty acids and $\alpha$-tocopheryl acetate. Anim. Feed Sci. Tech., 113: 223-238.

Roy S., Dontamalla S.K., Mondru A.K., Sannigrahi S., Veerareddy P.R. (2011). Downregulation of apoptosis and modulation of TGF- $\beta 1$ by sodium selenate prevents streptozotocin-induced diabetic rat renal impairment. Biol. Trace Elem. Res., 139: 55-71.

Rozbicka-Wi eczorek A.J., Szarpak E., Brzóska F., Śliwiński B., Kowalczyk J., Czauderna M. (2012). Dietary lycopenes, seleno-compounds and fish oil affect the profile of fatty acids and oxidative stress in chicken breast muscle. J. Anim. Feed Sci., 21: 705-724.

Rozbicka-Wieczorek A.J., Szarpak E., Brzóska F., Śliwiński B., Kowalczyk J., $\mathrm{C} \mathrm{z}$ a u d e r n a M. (2014). Efficiency of fatty acid accumulation into breast muscles of chickens fed diets with lycopene, fish oil and Se-compounds. Afr. J. Biotechnol., 13: in press.

Schweizer U., Streckfub F., Pelt P., Carlson B.A., Hatfield D.L., Köhrle J., S c ho m burg L. (2005). Hepatically derived selenoprotein P is a key factor to kidney but not for brain selenium supply. Biochem. J., 386: 221-226.

Š e v č i k o v a S., S k ř i v a n M., D l o u h a G. (2008). The effect of lycopene supplementation on lipid profile and meat quality of broiler chickens. Czech J. Anim. Sci., 53: 431-440.

Sicilia T., Bub A., Rechkemmer G., Kraemer K., Peter P. Hoppe P.P., Sabine E. K u 11 in g S.E. (2005). Novel lycopene metabolites are detectable in plasma of preruminant calves after lycopene supplementation. J. Nutr., 135: 2616-2621.

Tapi e ro H., Town send D.M., Tew K.D. (2003). The antioxidant role of selenium and selenocompounds. Biomed. Pharmacother., 57: 134-144. 
U 1 bri c h t T.L.V., S o u th g a t e D.A.T. (1991). Coronary heart disease: seven dietary factors. Lancet, 338: 985-992.

We is s W.P., H o g a n J.S. (2005). Effect of selenium source on selenium status, neutrophil function, and response to intramammary endotoxin challenge of dairy cows. J. Dairy Sci., 88: 4366-4374.

Yu L.L., Wang R.L., Z h a n g Y.Z., K l e e m a n n D.O., Z h u X.P., J i a Z.H. (2008). Effects of selenium supplementation on polyunsaturated fatty acid concentrations and antioxidant status in plasma and liver of lambs fed linseed oil or sunflower oil diets. Anim. Feed Sci. Tech., 140: 39-51.

Received: 3 XII 2013

Accepted: 8 IV 2014 